\title{
P75 ADVANCED CARE PLANNING FOR CHILDREN
}

Michael Miller Martin House, Wetherby, UK

10.1136/bmjspcare-2011-000105.75

Introduction Advanced care plans form many functions from acting as a vehicle for discussions to acting as a guide for provision of care in emergencies. Is it possible to satisfy these different demands?

Method With the support of a grant from the $\mathrm{DH}$ as part of the $£ 30$ million funding, a full day meeting was held to develop a Care Plan for children in Yorkshire and Humber. Parent's views were considered in the morning and provider views in the afternoon. Examples of existing care plans were shown to participants and parents spoke about the difficulty in making decisions. The relationship between PICU and palliative care was discussed.

Results The following outcomes were agreed:

- Care plans should be written for and held by parents

- Parents do not need to sign the care plans

- Care plans should include a guide to management of predicted symptoms

- There should be an agreed format of:

$\triangleright$ Brief description of present condition

$\triangleright$ List of contacts;

$\triangleright$ Brief description of management of symptoms, fits, chest infections etc

$\triangleright$ Management of slow decline

$\triangleright$ Management of sudden decline

$\triangleright$ Back page containing 'tick box' details of levels of resuscitation levels felt

$\triangleright$ To be appropriate for the child. 
- The meeting recognised that as the future is never known precisely, care plans need a degree of flexibility to be acceptable to all.

- Ideally there should be a mechanism to ensure care plans are reviewed and up to date.

- It was recognised that the initiation of such discussions is difficult and training would be helpful.

- A small leaflet for parents explaining what care plans are is to be developed.

Conclusion The development of recognisable care plans for child will help end of life care for children as well as supporting their families. 